\title{
Influence of awareness on the usage of motor third party insurance: a case study of Kampala district.
}

\author{
Henry Kitunzi ${ }^{1,2}$, Mirembe Helen ${ }^{1}$, Guma Consolate ${ }^{1}$
}

1. Innovative health Solutions, Policy and Development

2. Mirembe, Helen; Innovative health Solutions, Policy and development

\begin{abstract}
:
Background: Motor third party insurance was established in Uganda in 1989 as a social policy to protect motorists and other road users (third parties) in the event of an accident. However, reports show that only a few motorists filed claims to their insurers for compensation despite being involved in road traffic accidents.

Objective: To establish whether motorists' awareness has an influence on the usage of motor third party insurance.

Methods: This was a cross-sectional using both qualitative and qualitative methods. Data was collected from 384 motorists in Kampala district using structured and semi-structured questionnaires administered face-to-face. We also collected data from key informants (insurers, insurance regulators as well as enforcers - traffic police officers); and carried out desk review of motor third party insurance documents in Uganda.

Results: The results showed that 8 out of 10 motorists in Kampala did not understand motor third party insurance with $95.3 \%$ having no knowledge of their rights as policy holders and $87.8 \%$ having no knowledge of their obligations when involved in an accident. Majority of the motorists involved in accidents never made claims to their insurers for compensation.

Conclusion: The level of awareness among motorists concerning motor third party insurance was low which significantly affected their ability to file claims to their insurers following an accident. We recommended that motorists and the general public be educated on third party motor insurance.

Keywords: Awareness, usage, motor third party insurance, motorists, Kampala

DOI: http://dx.doi.org/10.4314/ahs.v16i4.36

Cite as: Kitunzi H, Mirembe H, Guma C. Influence of awareness on the usage of motor third party insurance. Afri Health Sci. 2016;16(4): 1169-1173. bttp:// dx.doi.org/10.4314/abs.v16i4.36
\end{abstract}

Background: Enter after the invention of the motor vehicle in 1886, it was realized that people were not in control of the machine. In other words, the machine had the potential to cause harm which might result in death. For that reason, the motor vehicle was named a lethal machine. A thought to counter this lethality was latter conceived, giving birth to Motor Vehicle Insurance1. In most countries, motor vehicle insurance is mandatory as a social policy to protect other road users (third parties) in the event of an accident meaning that third parties are compensated for damages inflicted on them by the accident. Motor vehicle insurance is termed differently in

\begin{tabular}{|l|}
\hline Corresponding author: \\
Henry Kitunzi, \\
Innovative health Solutions, \\
Policy and Development; International Health Sciences \\
Univesity, Health Policy and Management \\
Email: kitunzihenry@gmail.com \\
\end{tabular}

different countries with some referring to it as vehicle insurance, auto insurance, motor insurance and others car insurance. In Uganda, the basic form of motor vehicle insurance is called Motor Third Party Insurance (MTPI).

In 1989, the Uganda Parliament enacted the motor vehicle insurance (third party risks) Act which operationalized Motor Third Party Insurance (MPTI) policy. The act calls for compulsory insurance against third party risks in respect to the use of vehicles on public roads. It is therefore unlawful to use a vehicle on the road without a valid MTPI policy ${ }^{2}$.The primary social purpose of MTPI is to protect third parties against physical body injuries and economic losses arising from Road Traffic Accidents (RTA). MTPI therefore warrants that third party health is covered. That is, it provides financial support for treatment, rehabilitation and reimbursements for bodily injury, property damage or death of third parties.

Road transport is the dominant mode of transport in Uganda, with the vehicle population estimated to be African Health Sciences Vol 16 Issue 4, December, 2016 
around 800,000 to $1,000,000$ including motor $\mathrm{cycles}^{3}$. According to the WHO accident report 2011, Uganda ranks second in road fatality rates after Ethiopia; and Uganda Police statistics reported that Uganda had the highest number of road accident casualties in the Great Lakes region ${ }^{4,7}$. In Uganda, RTAs were observed to be on the increase which was attributed to a number of factors ranging from the poor road conditions, drunk driving, over speeding to carelessness use of roads by the public. Records at Mulago Hospital casualty ward showed that about twenty (20)RTA victims were received every hour ${ }^{5}$.

Injuries due to RTA present major public health problems in terms of morbidity, mortality, disability and the associated health care costs. They are estimated to claim 1.2 million lives annually and injuring and/or disabling between 20 million and 50 million people worldwide ${ }^{6}$. In addition, they have direct physical and psychological effects on the affected victims as well as their families, friends, and the communities. RTA injuries also have an enormous negative economic impact on individuals, families, communities, and the nation at large. It is estimated that they cost Low and Middle Income Countries (LMIC) between 1 and 2 percent of their Gross Domestic Product (GDP) ${ }^{6}$. According to World Report on Road Traffic Injury Prevention by WHO, health facilities and their resource constraint budgets, are greatly overstretched in dealing with survivors of RTAs ${ }^{6}$.

Despite the burden of RTAs and their after effects, road safety measures in place in Uganda are ineffective and third party policy has not fully played its role of ensuring that victims are compensated ${ }^{7}$.

It's against this background that we sought to establish whether awareness had an influence on the usage of MTPI in Kampala district the capital city of Uganda with largest number of motor vehicles and the highest number of RTA annually. Specifically the study was conducted to establish the level of awareness of motorists on MTPI and to determine the level of usage of MTPI by motorists in Kampala district.

In the study, Usage of MTPI was referred to as the ability of motorists to file claims to their insurers following an accident.

\section{Methods}

This was a cross-sectional study. Both quantitative andqualitative data was collected from 384 randomly selected motorists from Kampala district using structured and semi-structured questionnaires that were administered face-to-face. Kish and Leslie formula (1969) was used to calculate the sample size with an estimated prevalence of awareness among motorists of 50 per cent and the precision of the estimate of 5 per cent at 95 per cent confidence limit.

Kampala district was purposively due to the fact that it is the capital city of Uganda having that largest number of vehicles and the highest number of RTA annually. Qualitative data was collected from key informants (insurers, insurance regulators and law enforcement - Traffic Police Officers) using interview guides.

Data was standardised using quality control measures that included checking for consistency and completeness before the data entry process. Each questionnaire was be given a unique identification number.

With IBM SPSS Statistics version 22, Quantitative data was analysed using descriptive statistics methods (frequencies and percentages) and inferential statistics methods (Bivariate analysis to examine the relationship with the outcomes variable - usage of MTPI and the independent variables: comprehension and obligations of motorist; and logistic regression analysis to determine factors influencing usage of MTPI).

Qualitative data from both motorists and key informants was manually analysed using pre-determined themes: knowledge and usage of MTPI. Quotations that best represented emerging issues were included in the discussion. The study was approved by the Ethics Research Committee of the International Health Sciences University and participants signed a consent term to participate in the study.

\section{Results \\ Level of awareness of motorists of their rights and obligations around MTPI}

In this section we discuss motorists' level of awareness as follows: 1) Motorists' comprehension of Motor Third 
Party Insurance; 2) Motorists' right as MTPI policy holders; 3) Motorists' obligation as MTPI policy holders when involved in an accident.

Motorists' comprehension of Motor Third Party Insurance

Only $19.5 \%$ of the respondents had a clear comprehension of MTPI. Majority (80.5\%) did not understand MTPI with some noting that it is an annual tax paid by motor vehicles, others it is an insurance against traffic police disturbances, and a few, it is a license to drive on public roads. (Table 1).
Motorists' obligation as MTPI policy holders when involved in an accident

$46.1 \%$ of the respondents disclosed that to report to police was their obligation when involved in an accident, $28.1 \%$ to compensate the victim(s) on the spot, $12.2 \%$ to lodge in a claim to the insurers, $13.0 \%$ had no knowledge and $0.5 \%$ professed other obligations. This presents evidence that only $12.2 \%$ of the respondents who took part in the study knew their full obligation as policy holders in the event of an accident. Some respondents remarked that "... other than rushing to insurers to make claims, it is courteous to first save life by taking the victim(s) to a nearby health facility to receive treatment save life first, chase money latter on.” (Table 1).

Table 1: Percentages and Numbers of Participants' responses to comprehension of MTPI and Obligation as MTPI Policy holders in the event of an accident

\begin{tabular}{lll} 
& Percentage & Numbers \\
\hline Comprehension of MTPI & & \\
Tax paid annually & 40.6 & 156 \\
License to drive on the road & 34.9 & 134 \\
$\begin{array}{l}\text { Policy that protects you against third party liabilities } \\
\text { Insurance against Police disturbance }\end{array}$ & 19.5 & 75 \\
& 4.9 & 19 \\
\hline Obligation as MTPI Policy holder & \\
Tax paid annually & 40.6 & 156 \\
Licence to drive on the road & 34.9 & 134 \\
Policy that protects you against third party liabilities & 19.5 & 75 \\
Insurance against Police disturbance & 4.9 & 19 \\
\hline
\end{tabular}

\section{Level of usage of MTPI}

To determine whether motorists used MTPI (filled claims to their insurers following an accident), it was important to first ascertain whether they had been involved in an accident. The time period was limited to the past two years to avoid recall bias. (Table 2 ).
Results show that only 128 (33.3\%) out of 384 respondents who participated in the study had been involved in an accident in the past two (2) years. And out 128, only 40 $(31.3 \%)$ made claims to their insurers for compensation meaning majority, 87 (68.0\%) never filled claims. (Table 2) 


\begin{tabular}{lll} 
& Numbers & Percentage \\
\hline Whether involved in an accident while driving & & \\
Ever involved & 128 & 33.3 \\
Never involved & 249 & 64.8 \\
Not sure & 7 & 1.8
\end{tabular}

\begin{tabular}{lll}
\hline Whether a claim was made to the insurers after the accident & \\
Made & 40 & 31.3 \\
Never & 87 & 68.0 \\
Not sure & 1 & 0.8
\end{tabular}

\section{Inferential statistics}

A bivariate analysis $(\mathrm{p}<0.05)$ showed that both motorists' comprehension of MTPI $(\mathrm{X} 2=17.871, \mathrm{df}=3$ and $\mathrm{p}=0.000)$ and knowledge of their obligation as policy holders $(\mathrm{x} 2=26.401, \mathrm{df}=4$ and $\mathrm{p}=0.000)$ were significantly associated with usage of MTPI. A logistic regression $(\mathrm{p}<0.05)$ showed that motorists' knowledge of their obligation as policy holders $(\mathrm{OR}=1.8, \mathrm{Z}=3.56, \mathrm{p}=0.000$, $\mathrm{CI}=1.288-2.402)$ was more significantly associated to usage of MTPI than motorist' comprehension of MTPI $(\mathrm{OR}=1.6, \mathrm{Z}=2.73, \mathrm{P}=0.006, \mathrm{CI}=1.13-2.13)$.

\section{Discussion}

The results indicated that MTPI is not clearly understood in Uganda which is the case in all developing countries as portrayed by other scholars ${ }^{9}$. Most of the respondents in the study didn't even know that there existed an insurance policy which safeguards them against third party liabilities. They had misconceptions about MTPI with some perceiving it to be a warrant to drive freely on public roads and others a shield against traffic police disturbances. These misconceptions were attributed to the inability of the insurers and more so the regulators to educate motorists on issues pertaining to MTPI, particularly benefits, and how to realize these benefits following an accident. Another reason for the misconceptions could be due to the fact that the law which enacted MTPI was drafted in English yet the literacy level stands at 73 percent $^{10}$. At the time of this study nothing had been done to address these issues hence an urgent need to carry massive sensitization campaigns on MTPI and to translate the Act of Parliament into languages which most people can read and understand.

Majority of the respondents interviewed had no knowledge of their right and obligation around MTPI and surprisingly most of them expressed no interest in knowing more about the policy. They were biased with the way MTPI issues were handled and managed with some having had a bad experience with the claim processes. Some remarked "....that the policy has not benefited them at all. Another respondent stated that ".....it a crime not to have the policy on your car and when you have it, the police does not enlighten you on its sole purpose, then why bother knowing..."

Also the study indicated that majority of the motorists drove with caution to avoid accidents. However, a few who were involved, a greater proportion never made claims to their insurers for compensation. This is probably because they were not aware their entitlement as policy holders or, perhaps they didn't know the claim procedures. One of the respondents noted that, "... what I only know when involved in an accident with a third party, is either to take off, and when that is not possible, I negotiate to make a settlement with the victim(s). Another respondent indicated that, "...when I was involved in an accident, the police towed my car to Wandegeya police station. On making a follow-up, I was arrested. The police officer then 
asked whether I had a valid MTPI policy on my vehicle, which I had. Having it never secured my freedom instead the traffic officer who was handling my case compelled me to raise Uganda shillings, 1,300,000 to compensate the victims who had been admitted to Mulago hospital. I was rescued by my family after three days". From this it can be concluded that Police only act as enforcers and not advisers of MTPI policy. The law which operationalized MTPI policy mandates Police officers, specifically Traffic Police to produce accident reports which is one of the requirements needed to make an insurance settlement claim fruitful. However, they are only prepared upon request at a fee of Uganda shillings 78,000.

The study has demonstrated that motorists' awareness of MTPI greatly influences its usage - ability of a motorist to make a claim following an accident involving a third party with knowledge of knowing what to do being more significant than just knowing the existence of the policy. The study findings are in agreement with the findings of Farida (2013) who asserted that in Uganda ignorance costs motorists a lot of money. Even when they had upto-date MTPI policies, they settled third parties out of their pockets and never bothered to claim for reimbursements from their insurers.

\section{Conclusion and recommendations}

Motorists' awareness on MTPI significantly influenced its usage. In order to improve awareness, the study recommends that investment should be focused on educating and/or sensitizing motorists and the general public on issues concerning MTPI. The recommended education strategies are: incorporating MTPI into the National curriculum, conducting seminars and group discussions, and disseminating MTPI information overs radio and television programs as well as using Newspapers, magazines and other print media avenues. The study further recommended that the claim settlement procedure be revised in order to curb the associated bureaucracies and lastly the law which operationalized MTPI be revised and periodically reviewed to suit the prevailing socio-economic contexts.

\section{Study limitation}

The study results can, however be challenged as responses from Kampala metropolitan area alone may not ably represent national diversity and incidences to inform national policy on MTPI.

\section{Acknowledgements}

Miss. Daisy Mulilo, Titus Ochieng, and Mr. Nsubuga Godfrey.

\section{Authors' contributions}

All the authors were involved in the conceptualization, tool development, analysis of the data, and writing of the manuscript. All authors revised drafts, read and approved the final manuscript.

\section{Competing interests}

The authors declare that they have no competing interests.

\section{References}

1. Kipkirui, 2013: Motor Insurance: All you need to know (http://cic.co.ke/allyou- need-to- know-about motorvehicle-insurance/ (Accessed on 12/04/13)

2. Parliament of Uganda (1989): Motor Vehicle Insurance (Third Party Risks) Act 1989 (Ch. 214)

3. Ministry of Works and Transport (Transport Licencing Board) - 2015: Vehicles and Vehicle Inspections in Uganda: Progress and Plans

4. Uganda Police, 2011: Police report 2011

5. Mulago hospital, 2012: Medical report 2012

6. Word Bank, 2009: Motor Third Party liability Insurance. Market ranking report.

7. WHO, 2011: World Report on Road Traffic Injury Prevention

8. Ben Okiror, 2009: Third Party Insurance: Do you know your rights? (The New Vision Publications, 06/11/2009) 9. Serap O. Gonulal, 2009: Motor Third party Liability Insurance in Developing Countries. Raising Awareness and Improving Safety (The International Bank for Reconstruction and Development/The World Bank) 10.http://www.newvision.co.ug/new_vision/ news/1330222/uganda-falls-short-2015-adult-literacytarget - (Accessed on 08/July/2016) 